\title{
Chapter 10 \\ Primary Epithelial Ovarian Neoplasms: New Concepts Concerning Origin, Pathogenesis and Classification Based on Morphology, Immunomarkers, Molecular Features, and Gene Expression Studies
}

\author{
Bernard Czernobilsky, Leonor Leider-Trejo, Daniele Fanale, and Antonio Russo
}

Origin, Pathogenesis, Morphology, Classification Immunomarkers

The World Health Organization (WHO) classification of ovarian tumors, which first appeared in 1983 and since then has undergone a number of revisions, [1] is based on morphologic features as well as on the concept that each category of ovarian tumors develops from a specific ovarian cell. According to this histogenetic classification, all the epithelial ovarian neoplasms are derived from the ovarian surface epithelium and/or from ovarian inclusion cysts, which are lined by the above epithelial cells.

In recent years, a new approach to morphologic data, increasing presumptive evidence that the cell of origin of most, if not all, ovarian epithelial tumors may be extraovarian, especially from fallopian tube and uterine endometrial cells, the recognition of precursor lesions, the emergence of certain key immunomarkers as well as molecular and genetic factors [2-4] have brought about a reevaluation of the traditional approach to these tumors. This has resulted in attempts of reclassification or subclassification of ovarian epithelial neoplasms as well as new diagnostic criteria for these tumors [5]. It should also be stressed that in most cases these new concepts correlate with the clinical course of the disease and eventually may also have an impact on the therapeutic approach to these tumors.

\section{Origin and Pathogenesis of Epithelial Ovarian Neoplasms}

The long-standing classic theory that all types of ovarian epithelial neoplasm are derived from the ovarian surface epithelium (mesothelium) and/or from its stromal invaginations resulting in ovarian inclusion cysts has been challenged in recent years. Actually, the ovarian surface epithelium bears no resemblance to any of the different epithelial tumors, which involve the ovaries, and a

\footnotetext{
B. Czernobilsky $(\bowtie)$

Patho-Lab Diagnostics, Ness Ziona, Israel

e-mail: bc@patho-lab.com

L. Leider-Trejo

Institute of Pathology, Sourasky Medical Center, Tel Aviv, Israel

D. Fanale • A. Russo

Section of Medical Oncology, Department of Surgical and Oncological Sciences,

University of Palermo, Palermo, Italy
} 


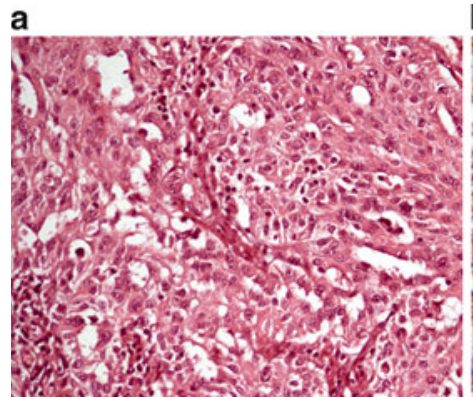

b

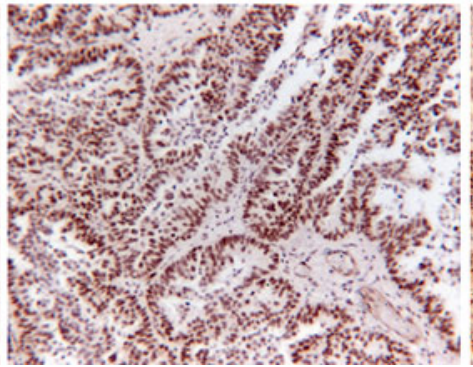

c

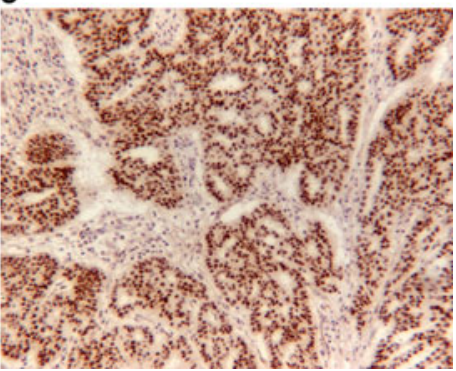

Fig. 10.1 (a) Ovarian high-grade serous carcinoma, (b) Positive WT1 and (c) Positive p53

questionable metaplastic process has been suggested to explain the apparent transformation of these ovarian surface cells to serous, endometrioid, mucinous, clear cell, and other epithelial neoplasm.

In recent years, entirely new concepts concerning the origin and pathogenesis of ovarian epithelial tumors have been advanced and were recently summarized by Kurman and Shih [4].

According to this hypothesis, most ovarian epithelial neoplasms are considered to be of extraovarian origin. Thus, it has been suggested that serous carcinomas develop from the fimbriated portion of the fallopian tube, endometrioid, and clear cell tumors from endometrial tissue passing through the fallopian tube resulting in endometriosis and mucinous as well as Brenner tumors arise from transitional-type epithelial nests at the tubal-mesothelial junction by a process of metaplasia.

Admittedly, much of the above still remains to be proven, but these preliminary data are of great interest and may find support in recent molecular and gene expression studies.

\section{Serous Tumors}

The vast majority of high-grade ovarian carcinomas are of the serous type. It is now being recognized that these tumors are morphologically very heterogenous which constitutes most likely an expression of their genetic heterogeneity [3]. Most serous carcinomas not only demonstrate papillary features, but also glandular, cribriform and solid architecture. Squamous metaplasia has also been described in these neoplasms. Thus, it may be difficult in some of these cases to differentiate serous from other ovarian epithelial tumors, such as endometrioid, mucinous, or clear cell carcinoma, when adhering only to the WHO classification and to the traditional morphologic criteria of ovarian tumors [3].

Most useful in the differential diagnosis between ovarian high-grade serous carcinoma and other epithelial neoplasms especially endometrioid carcinoma is widespread $\mathrm{WT}_{1}$ (Wilms tumor protein, a suppressor gene) expression [6] as well as p53 (tumor suppressor gene) overexpression and mutation which are characteristic for serous high-grade tumors and are absent in most other ovarian carcinomas (Fig. 10.1) [3, 7].

Furthermore, precursor lesions, such as the coexistence of a serous ovarian borderline tumor with an epithelial malignant neoplasm favors the diagnosis of ovarian low-grade serous carcinoma in the latter [8] while tubal intraepithelial carcinoma is characteristically associated with high-grade serous tumor (Fig. 10.2) [9].

\section{Mucinous Tumors}

Less than $3 \%$ of ovarian mucinous carcinomas of the intestinal type are primary tumors. The vast majority are metastatic from the intestinal tract [10]. 
a

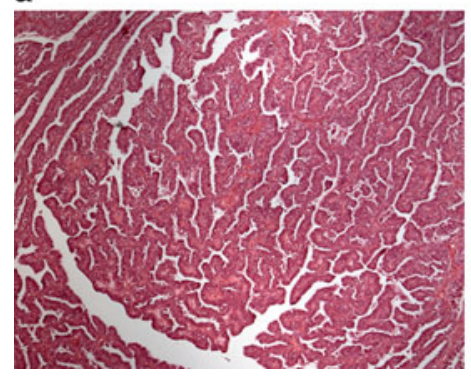

b

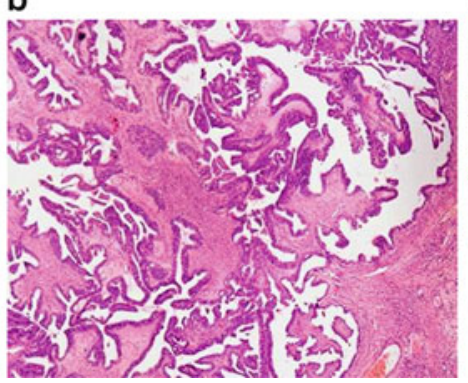

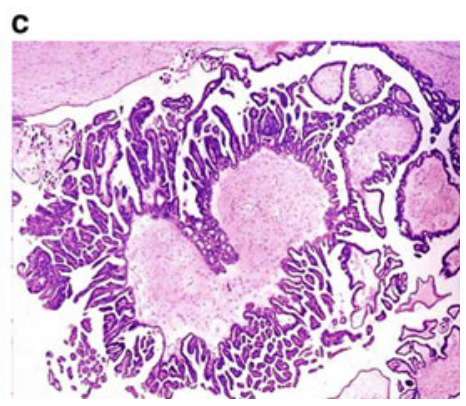

Fig. 10.2 (a) Ovarian low-grade serous carcinoma. Precursor lesions: (b) Borderline serous tumor (c) Micropapillary serous tumor
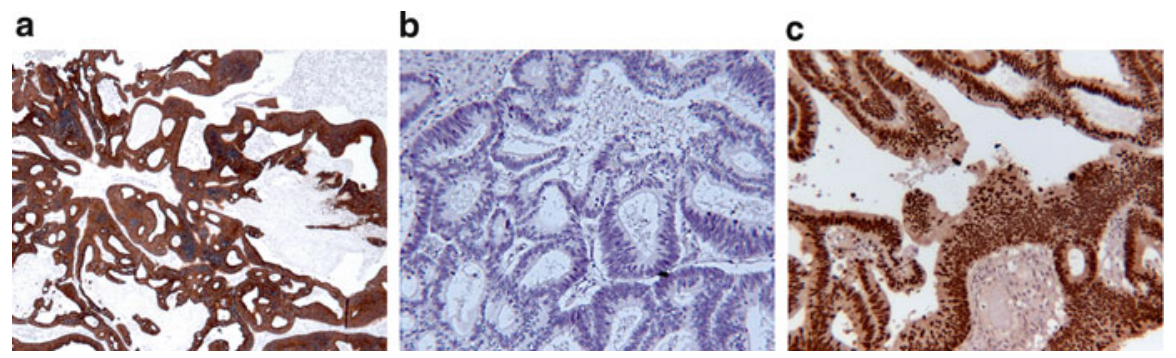

Fig. 10.3 Ovarian mucinous carcinoma metastatic from colonic carcinoma. (a) Positive cytokeratin 20, (b) Negative cytokeratin 7, (c) Positive CDX2

Most ovarian mucinous tumors are of the intestinal type. The so-called müllerian or seromucinous (endocervical) type ovarian tumors are uncommon. They are sometimes included in the group of mixed epithelial ovarian tumors [3].

Since many mucinous tumors lack apical mucin, they may be erroneously diagnosed as other ovarian epithelial neoplasms, especially as endometrioid carcinoma.

Immunohistochemical staining of these tumors is crucial in reaching a correct diagnosis, since primary mucinous tumors show predominantly cytokeratin 7 with lesser expression of cytokeratin 20. Most importantly, CDX2 is negative or occasionally only focally positive in primary mucinous ovarian tumors, while in metastatic carcinomas from the intestinal tract, CDX2 and cytokeratin 20 are strongly and diffusely positive while cytokeratin 7 is absent or only focally positive (Fig. 10.3) [11]. The precursor lesion of ovarian mucinous carcinoma is the mucinous borderline tumor (Fig. 10.4).

\section{Endometrioid Tumors}

According to Czernobilsky et al. [12], ovarian endometrioid carcinoma constituted about $23 \%$ of all ovarian primary carcinomas in 1970.

With the emergence of immunohistochemical markers, the recognition of precursor lesions and the change in our approach to classic morphologic features endometrioid carcinoma nowadays represents only about $10 \%$ of all ovarian carcinomas [13]. Many of erroneously diagnosed endometrioid carcinomas are indeed serous tumors. 
a

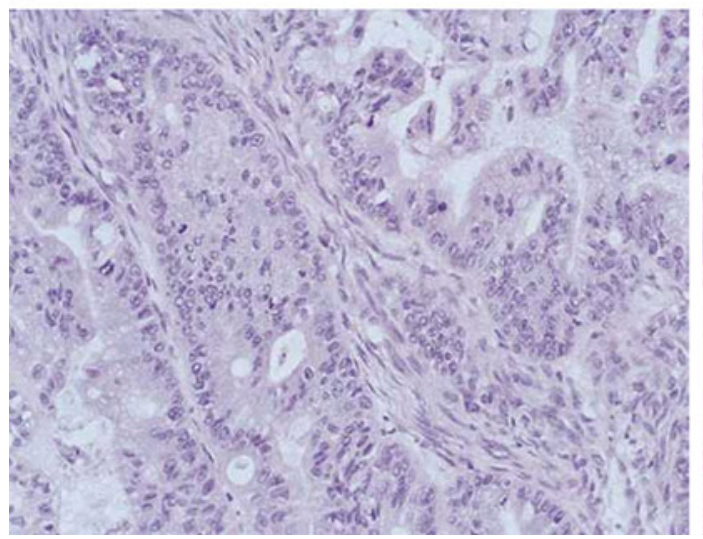

b

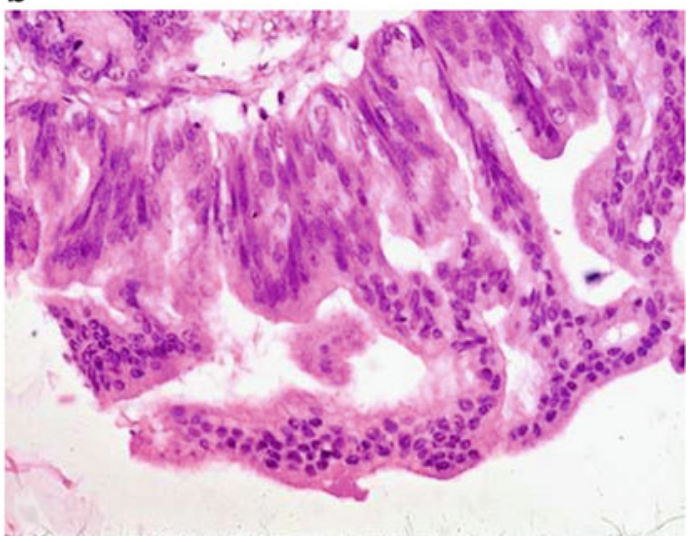

Fig. 10.4 (a) Primary ovarian mucinous carcinoma. Precursor lesion: (b) Borderline mucinous tumor

a

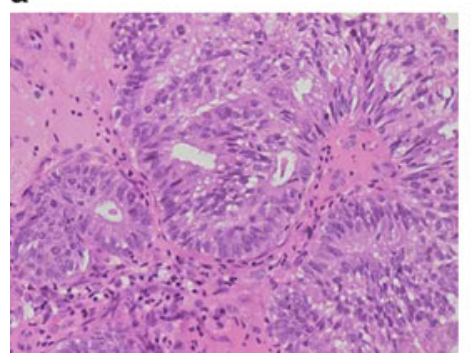

b

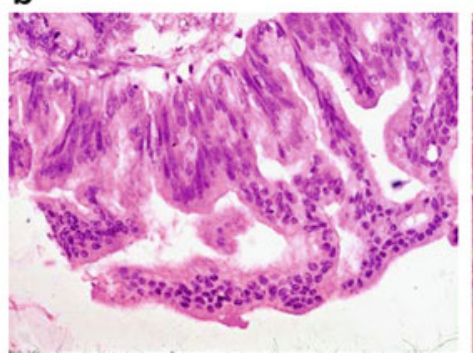

c

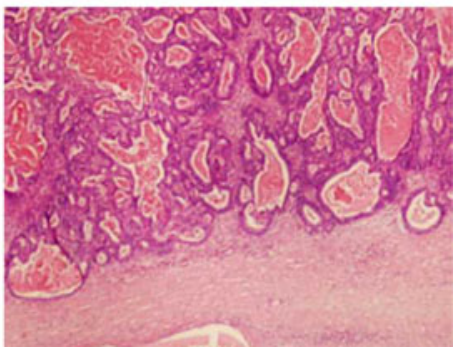

Fig. 10.5 (a) Ovarian endometrioid carcinoma. Precursor lesions: (b) Endometrioid adenofibroma (c) Borderline endometrioid tumor

Thus, endometrioid carcinomas are commonly associated with endometriosis, endometrioid adenofibroma, endometrioid borderline tumors as well as synchronous endometrioid intrauterine carcinoma [2, 3, 14]. These precursor lesions are absent in serous carcinomas (Fig. 10.5). Finally, endometrioid carcinomas in contrast to serous carcinomas, lack $\mathrm{WT}_{1}$ [15] and p53 overexpression, and usually express estrogen and progesterone receptors [3].

\section{Clear Cell Tumors}

This tumor shows a papillary, tubulocystic, and solid architecture with typical hobnail type and clear cells. An oxyphilic cell type has also been described. A typical feature of these tumors is the large, highly atypical nuclei with large nucleoli.

Positive stainings for estrogen and progesterone receptors as well as $\mathrm{WT}_{1}$ expression exclude a diagnosis of clear cell carcinoma [16]. P53 may be evident but not in the diffuse, prominent way as it is seen in serous tumors [17]. Hepatocyte nuclear factor (HNF) $1 \mathrm{~b}$ (1beta) has been recently described as a reliable immunomarker in ovarian clear cell tumors [18, 19]. 
a
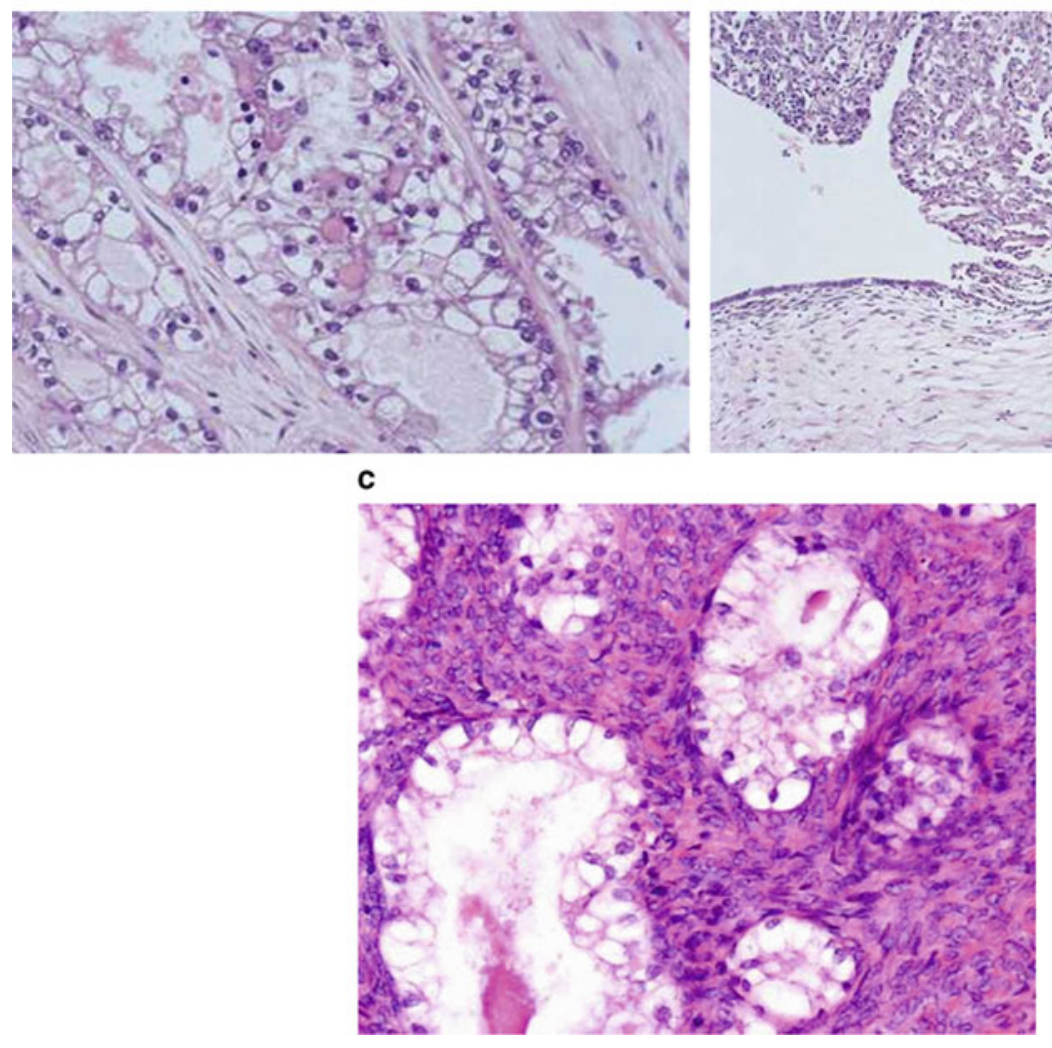

b

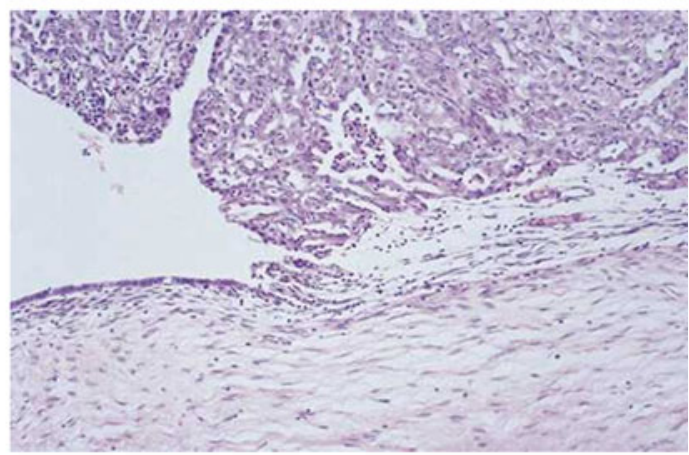

Fig. 10.6 (a) Ovarian clear cell carcinoma Precursor lesions: (b) Endometriosis with contiguous clear cell carcinoma (c) Clear cell adenofibroma

Ovarian carcinomas composed of clear cell elements mixed with other cell types, such as endometrioid or serous carcinoma should not be diagnosed as clear cell carcinoma but rather as serous carcinoma [20]. In other words, the diagnosis of clear cell carcinoma should be reserved for tumors with a homogenous clear cell population and highly atypical nuclei [21].

Precursor lesions of clear cell carcinoma include endometriosis and clear cell adenofibromas (Fig. 10.6) [2].

\section{Transitional Cell Tumors}

Most of the tumors classified as transitional cell carcinoma in the WHO classification [1] are actually high-grade serous or high-grade endometrioid carcinomas and frequently express p53 and $\mathrm{WT}_{1}$, which are typical of serous carcinomas (Fig. 10.7) [22]. The only exception appears to be the benign Brenner tumor which is positive for uroplakin and may thus be of urothelial derivation (Fig. 10.8) [23]. 
Fig. 10.7 Ovarian transitional cell carcinoma morphologically resembling urothelial cancer but representing high-grade serous carcinoma

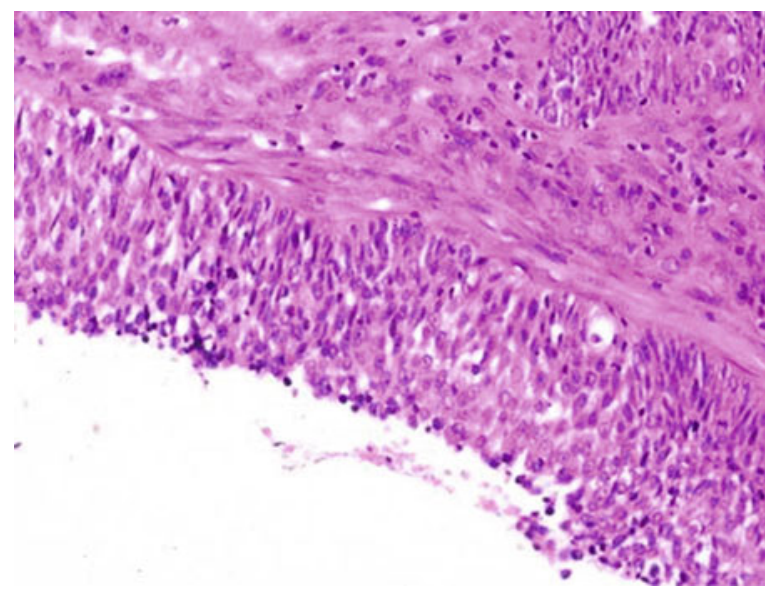

Fig. 10.8 Benign ovarian Brenner tumor

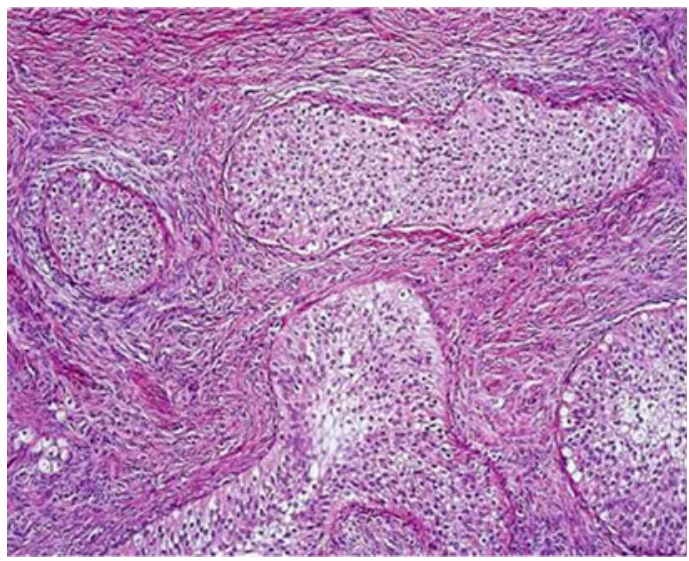

\section{Mixed Epithelial Ovarian Tumors}

These are tumors showing two or more distinctive types of neoplasms constituting at least $10 \%$ of the tumor. According to Soslow [3], the tumor elements in mixed epithelial tumors should be separable and as such diagnosable as separate neoplasms. Notwithstanding the above definition of mixed epithelial tumors, most of these are considered to be high-grade serous carcinomas, which are supported by diffuse $\mathrm{WT}_{1}$ staining [3].

\section{Undifferentiated Carcinomas}

Most of these tumors which are not histologically classifiable should also be diagnosed as highgrade serous carcinomas especially if the tumor is $\mathrm{WT}_{1}$ positive [3] and other possibilities, such as metastases to the ovary are excluded (Fig. 10.9). Tables 10.1-10.3 summarize some of the above discussed data. 
a

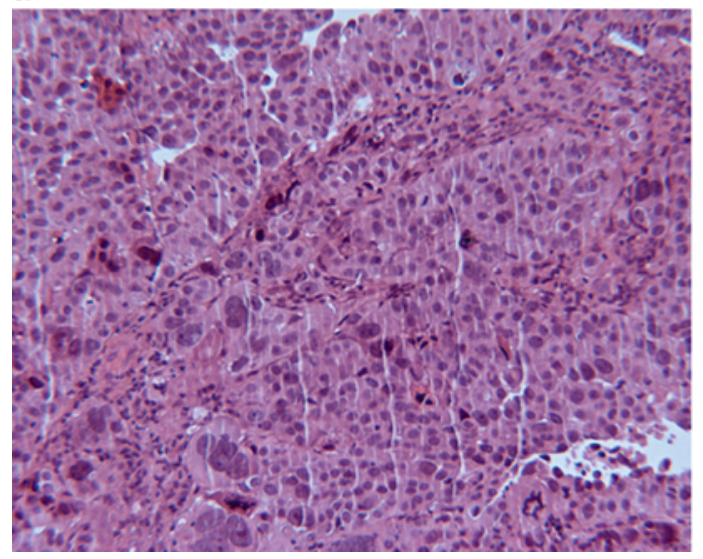

b

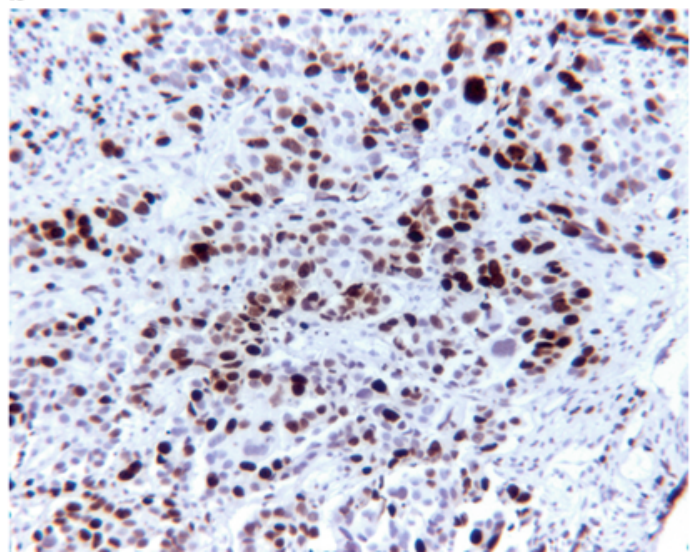

Fig. 10.9 (a) Ovarian undifferentiated carcinoma (b) Positive WT1

Table 10.1 Proposed subclassification of primary ovarian epithelial tumors [5]

1. High-grade serous, high-grade endometrioid and undifferentiated carcinomas

2. Low-grade serous carcinomas and serous borderline tumors

3. Mucinous carcinomas and mucinous borderline tumors of intestinal type

4. Low-grade endometrioid carcinoma and endometrioid borderline tumors

5. Clear cell carcinomas

6. Transitional cell carcinomas

Table 10.2 Precursor lesions in ovarian carcinomas

\begin{tabular}{ll}
\hline Carcinoma & Precursor lesions \\
\hline Serous (high grade) & Fallopian tube intraepithelial carcinoma \\
Serous (low grade) & Serous borderline tumor \\
Mucinous (intestinal type) & Mucinous borderline tumor \\
Endometrioid & Endometriosis \\
& Endometrioid borderline tumor \\
& Synchronous intrauterine endometrioid carcinoma \\
Clear cell & Endometriosis \\
& Clear cell adenofibroma \\
& Clear cell borderline tumor \\
Undifferentiated & Unknown \\
Mixed & Unknown \\
\hline
\end{tabular}

Table 10.3 ER, WT1, P53 in ovarian carcinomas

\begin{tabular}{llll}
\hline Ovarian carcinomas & ER & WT1 & p53 \\
\hline Serous, high grade & - & + & + \\
Serous, low grade & + & - & - \\
Mucinous (intestinal type) & - & - & - \\
Endometrioid & + & - & - \\
Clear cell & - & - & + (variable) \\
Transitional cell (Brenner tumor excluded) & - & + & + \\
Undifferentiated $^{\mathrm{a}}$ & - & + & + \\
Mixed $^{\mathrm{b}}$ & - & + & + \\
\hline
\end{tabular}

ER Estrogen receptor

${ }^{a}$ Usually represents high-grade serous carcinoma

${ }^{b}$ Frequently shows a significant component of high-grade serous carcinoma 


\section{Summary}

The emergence of new data in recent years concerning the origin and pathogenesis of epithelial ovarian carcinomas culminating in a theory that the latter are of extraovarian origin, the morphologic variability of hitherto well-defined ovarian tumors, the presence of precursor lesions, relatively specific immunohistochemical markers as well as molecular and genetic features, require a reassessment of various aspects of ovarian epithelial tumors.

In addition, it has been proposed by Kurman et al. [2, 4, 24] that ovarian epithelial tumors be divided in type I and type II tumors, similar to the already existing division of endometrial uterine carcinoma.

According to this proposal, type I tumors which are relatively genetically stable consist of micropapillary serous, mucinous, and endometrioid carcinomas. Type II tumors are genetically highly unstable aggressive neoplasms, such as high-grade serous carcinomas, carcinosarcomas, and undifferentiated carcinoma.

The two groups vary in their histologic appearance, precursor lesions, and immunophenotype as well as by molecular and genetic features. The clinical course and prognosis also differ in these two groups. Since clear cell carcinomas show clinical morphological, immunohistochemical, and genetic features which are shared to some degree by both type I and type II ovarian tumors, they cannot at this time be definitely classified [2].

Finally, it is to be expected that a different therapeutic approach to patients with group I and II tumors, including screening and prevention may result in a more favorable response and improve prognosis especially in the patients with high-grade ovarian cancer.

\section{Molecular Features and Gene Expression Studies}

Despite the poor prognosis and the importance of early diagnosis, there are no reliable methods for detection of ovarian cancer in the early stages of disease. Since patients diagnosed with stage I epithelial ovarian cancers (EOCs) have a $90 \%$ survival rate, it is important to identify novel ovarian cancer biomarkers with potential utility in early stage screening. Little is known of the molecular genetic changes that are associated with the development of invasive ovarian cancer. Cytogenetic analyses of epithelial ovarian tumors have shown frequent structural aberrations of chromosomes 1 , 3,6 , and 11, suggesting that inactivation of genes located on these chromosomes may be important in ovarian tumorigenesis. A high frequency of allelic losses $(\mathrm{LOH})$ was observed on $11 \mathrm{p}, 13 \mathrm{q}$, and $17 \mathrm{p}$. The loss of tumor-suppressor genes on $13 \mathrm{q}$ and $17 \mathrm{p}$ may be involved in early events of ovarian tumorigenesis and changes on $11 \mathrm{p}$ in later events [25].

With regard to the application of new genomic technologies, the gene expression analysis has allowed to identify important differentially expressed genes and molecular pathways that may help to understand the evolution from normal ovarian tissue to ovarian cancer [26]. Several studies have shown distinctive gene expression patterns that can differentiate between histological subtypes of ovarian carcinoma [27-31] or predict response to chemotherapy or survival [32-35]. The different histological subclasses and the clinical phenotypes displayed by EOCs are hypothesized to be driven by specific genes. Differentially expressed genes are included in pathways involved in chromosomal instability, invasion cell, motility, proliferation, and gene silencing and provided new insights into the origin of this cancer [36]. In addition, differences in gene expression patterns may help to characterize ovarian cancer and to identify potential targets for effective prevention and treatment of disease. Normal epithelial ovarian samples have been compared with tumor samples in gene expression profiling studies, generating very distinct groups in hierarchical clustering. 
Table 10.4 Gene signatures associated with epithelial ovarian cancers

\begin{tabular}{|c|c|c|}
\hline Histological subtypes & Differentially expressed genes & References \\
\hline Serous & FOLR1, PTGS1, WT1, GAS6 & [41] \\
\hline Endometrioid & TFF3, SFN, MSX1, CEACAM1b & [41] \\
\hline Mucinous & $\begin{array}{l}E R B B 3, C C N D 1, T G F-\mathrm{a} \\
K-r a s 2, c-J U N, Y E S 1, E C T 2 \\
C A V-1, S P R Y 1 \\
C D C 42, R A C 1, I Q G A P 2, R A L A, \text { Cortactin } \\
A B C C 6, A B C C 3\end{array}$ & [42] \\
\hline Clear cell & $\begin{array}{l}\text { SOD2, GPX3, RBP4, UGT1A1, TFPI2, FXYD2, GLRX, } \\
\quad \text { ANXA4 }\end{array}$ & $\begin{array}{l}{[38]} \\
{[29]}\end{array}$ \\
\hline
\end{tabular}

The choice of a normal control that can be compared to EOC samples in microarray analyses can strongly influence the identification of differentially expressed genes. Seventy-five gene expression profiles of EOC subhistotypes were compared by Zorn et al. to determine the similarities and differences between all samples. The gene signature generated from Zorn et al. identified 166 genes that distinguished the samples into three subtypes: endometrioid, serous, and clear cell [37]. Instead, Schwartz et al. found 158 differentially expressed genes histotype-specific for the endometrioid, serous, clear cell, and mucinous ovarian cancers. Of these 158 genes, 73 genes were clear cell histotype-specific, 64 genes were mucinous histotype-specific, 19 genes were specific for serous, and 2 genes were specific for endometrioid. These data showed that there are large expression differences between the various histological types of ovarian cancer [38]. There is a small set of upregulated genes related to ovarian clear cell tumors including SOD2 (superoxide dismutase), GPX3 (glutathione peroxidase 3), RBP4 (retinol binding protein 4), UGT1A1 (UDP glycosyltransferase1family, polypeptideA1), TFPI2 (tissue factor pathway inhibitor), FXYD2 (FXYD domain containing ion transport regulator 2), GLRX (Glutaredoxin), and ANXA4 (Annexin). These genes overlap with genes identified by Zorn et al. [29]. Two of these genes are associated with chemotherapy response: UGT1A1 detoxifies the active metabolite of irinotecan, whereas ANXA4 has been associated with paclitaxel resistance $[39,40]$. SOD2, GLRX, and GPX3 are involved in oxidative stress response and particularly high levels of these in clear cell histotypes may make these tumors more resistant to chemotherapy [38] (Table 10.4).

A microarray analysis of 103 primary ovarian cancers has suggested the contributions of origin and histotype on the tumor gene expression profile [41]. Sixty-two differentially expressed genes were observed between endometrioid versus serous histotypes. Of these 62 genes, endometrioid carcinomas often showed highly expressed TFF3 (trefoil factor 3), SFN (stratifin), MSX1 (msh homeobox 1), and CEACAMIb (carcinoembryonic antigen-related cell adhesion molecule) genes. Serous carcinomas often showed high expression of the following genes: FOLRI (folate receptor 1), PTGS1 (prostaglandin-endoperoxide synthase 1), WT1 (Wilms tumor 1), and GAS6 (growth arrest-specific 6). By an extensive Affymetrix microarray analysis, mucinous ovarian cancer was differentiated from the other subtypes of ovarian cancer, due to different gene expression profiles [38, 42, 43]. In mucinos ovarian tumors, Wamunyokoli et al. [42] identified specific differentially expressed genes involved in the following pathways: proliferation and cell cycle regulation (ERBB3, $C C N D 1, T G F$-a), transformation (K-ras2, c-JUN, YES1, ECT2), signal transduction $(C A V-1$ and $S P R Y 1)$, cytoskeleton rearrangement/signal transduction (CDC42, RAC1, IQGAP2, RALA, Cortactin), and drug resistance ( $A B C C 6$ and $A B C C 3)$.

In conclusion, clear cell, serous, endometrioid, and mucinous histotypes appear to show specific gene expression signatures. These differences in gene expression profiles could be useful in the treatment of the different histotypes. 
Using a Serial Analysis of Gene Expression (SAGE), David G. Peters et al. [44] have identified several potentially novel biomarkers whose expression is elevated in ovarian cancer. These proteins include CD9, HMGA1, AHCY, GNAI2, CCT3, and TACC3.

Moreover, it has recently been demonstrated by some research groups that the gene expression signatures determined by microarray analysis may act as a prognostic factor in EOC [45]. Several markers with prognostic value have been identified by specific molecular studies. HER2/neu and EGFR overexpression has been related to poor prognosis [46-48]. Clinical studies have shown that TP53 overexpression is related with shorter survival in ovarian cancer [49] and resistance to platinum-based chemotherapy [50]. Other molecular studies by microarray identified several genes responsible for platinum resistance involved in the following pathways: proliferation (FRA1, ETV4, IGFBP3, STAT1), cell-cycle control (CDKN1A, CDKN1C, CDC25C, PLK3), apoptosis (BAK, BAX, STAT1, c-JUN, TP53), DNA repair (XRCC9, PCNA, TP53, DDB2, GADD45B, POLH), and energy regulation metabolism (STARD4 and FDXR) [51]. Nevertheless, the $N A C$ - 1 expression modulates taxol resistance in ovarian cancer and may provide an effective target for chemotherapeutic intervention in taxol-resistant tumors [52]. The loss of protein p27 is an important prognostic marker for predicting disease recurrence in primary ovarian cancer [53]. Moreover, the amplification of oncogene $M Y C$ and increased expression levels of cyclin $\mathrm{E}$ have been associated with poor prognosis [54, 55]. In a recent work [56], the mammaglobin B $(M G B-2)$ gene expression was evaluated in ovarian cancer tissues and in normal ovarian controls by quantitative real-time PCR and then by immunohistochemistry. MGB-2 expression levels were found increased in EOC compared to normal ovarian controls, both at protein level and mRNA. $M G B-2$ expressing tumors were related to clinicopathologic features of the less aggressive tumors. This finding suggest that $M G B-2$ is an independent prognostic marker in EOC and its expression is correlated with reduced risk of disease recurrence [56].

Moreover, for the first time, the epithelial cell adhesion molecule (Ep-CAM) overexpression was associated with a decreased overall survival. Ep-CAM represents a novel independent prognostic marker for reduced survival of patient with EOC [57].

In conclusion, whole genome expression profiling has become a vital tool for identifying differentially expressed genes in EOCs, in order to potentially prolong the survival of women diagnosed with this disease [58].

\section{References}

1. Tavassoli FA, Devillee P, editors. Pathology and genetics: tumours of the breast and female genital organs. World Health Organization Classification of Tumours. Lyon: IARC; 2003.

2. Kurman RJ, Shih I. Pathogenesis of ovarian cancer: lessons from morphology and molecular biology and their clinical implications. Int J Gynecol Pathol. 2008;27:151-60.

3. Soslow RA. Histologic subtypes of ovarian carcinoma: an overview. Int J Gynecol Pathol. 2008;27:161-74.

4. Kurman RJ, Shih I. The origin and pathogenesis of epithelial ovarian cancer: a proposed unifying theory. Am J Surg Pathol. 2010;34:433-43.

5. Gilks CB. Subclassification of ovarian surface epithelial tumors based on correlation of histologic and molecular pathologic data. Int J Gynecol Pathol. 2004;23:200-5.

6. Hwang H, Quenneville L, Yaziji H, et al. Wilms tumor gene product: sensitive and contextually specific marker of serous carcinomas of ovarian surface epithelial origin. Appl Immunohistochem Mol Morphol. 2004;12:122-6.

7. Leitao MM, Soslow RA, Baergen RN, et al. Mutation and expression of TP53 gene in early stage epithelial ovarian carcinoma. Gynecol Oncol. 2004;93:301-6.

8. Singer G, Kurman RJ, Chang HW, et al. Diverse tumorigenic pathways in ovarian serous carcinoma. Am J Pathol. 2002;160:1223-8.

9. Medeiros F, Muto MG, Lee Y, et al. The tubal fimbria is a preferred site for early adenocarcinoma in women with familial ovarian cancer syndrome. Am J Surg Pathol. 2006;30:230-6. 
10. Seidman JD, Kurman RJ, Ronnett BM. Primary and metastatic mucinous adenocarcinomas in the ovaries: incidence in routine practice with a new approach to improve intraoperative diagnosis. Am J Surg Pathol. 2003; 27:985-93.

11. Groisman GM, Meir A, Sabo E. The value of CDx2 immunostaining in distinguishing primary ovarian carcinomas from colonic carcinoma metastatic to the ovaries. Int J Gynecol Pathol. 2004;23:52-7.

12. Czernobilsky B, Silverman BB, Mikuta JJ. Endometrioid carcinoma of the ovary. A clinicopathologic study of 75 cases. Cancer. 1970;26:1141-52.

13. Seidman JD, Horkayne-Szakaly I, Haiba M, et al. The histologic type and stage distribution of ovarian carcinomas of surface epithelial origin. Int J Gynecol Pathol. 2004;23:41-4.

14. Roth LM, Emerson RE, Ulbright TM. Ovarian endometrioid tumors of low malignant potential: a clinicopathologic study of 30 cases with comparison to well-differentiated endometrioid adeno-carcinoma. Am J Surg Pathol. 2003;27:1213-59.

15. Shimizu M, Tok T, Takagi Y, et al. Immunohistochemical detection of the Wilms tumor gene (WT1) in epithelial ovarian tumors. Int J Gynecol Pathol. 2000;19:158-63.

16. Waldstrom M, Grove A. Immunohistochemical expression of Wilms tumor gene protein methylation in ovarian clear cell adenocarcinoma. Arch Pathol Lab Med. 2005;129:85-8.

17. Otis CN, Krebs PA, Quezado MM, et al. Loss of heterozygosity in p53, BRACA1, and estrogen receptor genes and correlation to expression of p53 protein in ovarian epithelial tumors of different cell types and biology behavior. Hum Pathol. 2000;31:233-48.

18. Köbel M, Kallogeer SE, Carrick J, Huntsman D, Asad H, Oliva E, et al. A limited panel of immunomarkers can reliably distinguish between clear cell and high grade serous adenocarcinoma of the ovary. Am J Surg Pathol. 2009;33:14-21.

19. Stadlmann S, Gueth U, Baumhoer D, et al. Glypican-3 expression in primary and recurrent ovarian carcinomas. 2007;26:341-44.

20. Silva EG, Young RH. Endometrioid neoplasms with clear cells: a report of 125 cases in which the alteration is not of typical secretory type. Am J Surg Pathol. 2007;31:1203-8.

21. Han G, Gilks CB, Leung S, et al. Mixed ovarian epithelial carcinomas with clear cell and serous components are variants of high grade serous carcinomas: an interobserver correlative and immunohistochemical study of 32 cases. Am J Surg Pathol. 2008;32:955-64.

22. Logani S, Oliva E, Amin MB, et al. Immunoprofile of ovarian tumor with putative transitional cell (urothelial) differentiation using novel utothelial markers: histogenetic and diagnostic implications. Am J Surg Pathol. 2003;27:1434-41.

23. Riedel L, Czernobilsky B, Lifschitz-Mercer B, et al. Brenner tumors but not transitional cell carcinomas of the ovary show urothelial differentiation: an immunohistochemical study including cytokeratins and uroplakin. Virchows Arch. 2001;438:181-91.

24. Kurman RJ, McConnell TG. Precursors of endometrial and ovarian carcinoma. Arch Virchows. 2010;456:1-12.

25. Gallion HH, Powell DE, Morrow JK, et al. Molecular genetic changes in human epithelial ovarian malignancies. Gynecol Oncol. 1992;47:137-42.

26. Grisaru D, Hauspy J, Prasad M, et al. Microarray expression identification of differentially expressed genes in serous epithelial ovarian cancer compared with bulk normal ovarian tissue and ovarian surface scrapings. Oncol Rep. 2007;18:1347-56.

27. Marquez RT, Baggerly KA, Patterson AP, et al. Patterns of gene expression in different histotypes of epithelial ovarian cancer correlate with those in normal fallopian tube, endometrium, and colon. Clin Cancer Res. 2005;11:6116-26.

28. Meinhold-Heerlein I, Bauerschlag D, Hilpert F, et al. Molecular and prognostic distinction between serous ovarian carcinomas of varying grade and malignant potential. Oncogene. 2005;24:1053-65.

29. Zorn KK, Bonome T, Gangi L, et al. Gene expression profiles of serous, endometrioid, and clear cell subtypes of ovarian and endometrial cancer. Clin Cancer Res. 2005;11:6422-30.

30. Ouellet V, Provencher DM, Maugard CM, et al. Discrimination between serous low malignant potential and invasive epithelial ovarian tumors using molecular profiling. Oncogene. 2005;24:4672-87.

31. Gilks CB, Vanderhyden BC, Zhu S, et al. Distinction between serous tumors of low malignant potential and serous carcinomas based on global mRNA expression profiling. Gynecol Oncol. 2005;96:684-94.

32. Berchuck A, Iversen ES, Lancaster JM, et al. Patterns of gene expression that characterize long-term survival in advanced stage serous ovarian cancers. Clin Cancer Res. 2005;11:3686-96.

33. Bernardini M, Lee CH, Beheshti B, et al. High-resolution mapping of genomic imbalance and identification of gene expression profiles associated with differential chemotherapy response in serous epithelial ovarian cancer. Neoplasia. 2005;7:603-13.

34. Spentzos D, Levine DA, Ramoni MF, et al. Gene expression signature with independent prognostic significance in epithelial ovarian cancer. J Clin Oncol. 2004;22:4700-10. 
35. Spentzos D, Levine DA, Kolia S, et al. Unique gene expression profile based on pathologic response in epithelial ovarian cancer. J Clin Oncol. 2005;23:7911-8.

36. Farley J, Ozbun LL, Birrer MJ. Genomic analysis of epithelial ovarian cancer. Cell Res. 2008;18:538-48.

37. Zorn KK, Jazaeri AA, Awtrey CS, et al. Choice of normal ovarian control influences determination of differentially expressed genes in ovarian cancer expression profiling studies. Clin Cancer Res. 2003;9:4811-8.

38. Schwartz DR, Kardia SL, Shedden KA, et al. Gene expression in ovarian cancer reflects both morphology and biological behavior, distinguishing clear cell from other poor-prognosis ovarian carcinomas. Cancer Res. 2002;62:4722-9.

39. Han EK, Tahir SK, Cherian SP, et al. Modulation of paclitaxel resistance by annexin IV in human cancer cell lines. Br J Cancer. 2000;83:83-8.

40. Gagne JF, Montminy V, Belanger P, et al. Common human UGT1A polymorphisms and the altered metabolism of irinotecan active metabolite 7-ethyl-10-hydroxycamptothecin (SN-38). Mol Pharmacol. 2002;62:608-17.

41. Shedden KA, Kshirsagar MP, Schwartz DR, et al. Histologic type, organ of origin, and Wnt pathway status: effect on gene expression in ovarian and uterine carcinomas. Clin Cancer Res. 2005;11:2123-31.

42. Wamunyokoli FW, Bonome T, Lee JY, et al. Expression profiling of mucinous tumors of the ovary identifies genes of clinicopathologic importance. Clin Cancer Res. 2006;12(3 Pt 1):690-700.

43. Heinzelmann-Schwarz VA, Gardiner-Garden M, Henshall SM, et al. A distinct molecular profile associated with mucinous epithelial ovarian cancer. Br J Cancer. 2006;94:904-13.

44. Peters DG, Kudla DM, DeLoia JA, et al. Comparative gene expression analysis of ovarian carcinoma and normal ovarian epithelium by serial analysis of gene expression. Cancer Epidemiol Biomarkers Prev. 2005;14:1717-23.

45. Jochumsen KM, Tan Q, Høgdall EV, et al. Gene expression profiles as prognostic markers in women with ovarian cancer. Int J Gynecol Cancer. 2009;19:1205-13.

46. Kokuho M, Yoshiki T, Hamaguchi A, et al. Immunohistochemical study of c-erbB-2 proto-oncogene product in prostatic cancer. Nippon Hinyokika Gakkai Zasshi. 1993;84:1872-8.

47. Meden H, Kuhn W. Overexpression of the oncogene c-erbB-2 (HER2/neu) in ovarian cancer: a new prognostic factor. Eur J Obstet Gynecol Reprod Biol. 1997;71:173-9.

48. Skirnisdottir I, Sorbe B, Seidal T. The growth factor receptors HER-2/neu and EGFR, their relationship, and their effects on the prognosis in early stage (FIGO I-II) epithelial ovarian carcinoma. Int J Gynecol Cancer. 2001;11:119-29.

49. Ozalp SS, Yalcin OT, Basaran GN. Prognostic significance of deletion and overexpression of the p53 gene in epithelial ovarian cancer. Eur J Gynaecol Oncol. 2000;21:282-6.

50. Reles A, Wen WH, Schmider AG, et al. Correlation of p53 mutations with resistance to platinum-based chemotherapy and shortened survival in ovarian cancer. Clin Cancer Res. 2001;7:2984-97.

51. Konstantinopoulos PA, Spentzos D, Cannistra SA. Gene-expression profiling in epithelial ovarian cancer. Nat Clin Practice Oncol. 2008;5(10):577-87.

52. Ishibashi M, Nakayama K, Yeasmin S, et al. A BTB/POZ gene, NAC-1, a tumor recurrence-associated gene, as a potential target for taxol resistance in ovarian cancer. Clin Cancer Res. 2008;14(10):3149-55.

53. Masciullo V, Sgambato A, Pacilio C, et al. Frequent loss of expression of the cyclin-dependent kinase inhibitor p27 in epithelial ovarian cancer. Cancer Res. 1999;59:3790-4.

54. Diebold J, Suchy B, Baretton GB, et al. DNA ploidy and MYC DNA amplification in ovarian carcinomas. Correlation with p53 and bcl-2 expression, proliferative activity and prognosis. Virchows Arch. 1996;429:221-7.

55. Farley J, Smith LM, Darcy KM, et al. Cyclin E expression is a significant predictor of survival in advanced, suboptimally debulked ovarian epithelial cancers: a Gynecologic Oncology Group study. Cancer Res. 2003;63:1235-41.

56. Tassi RA, Calza S, Ravaggi A, et al. Mammaglobin B is an independent prognostic marker in epithelial ovarian cancer and its expression is associated with reduced risk of disease recurrence. BMC Cancer. 2009;9:253.

57. Spizzo G, Went P, Dirnhofer S, et al. Overexpression of epithelial cell adhesion molecule (Ep-CAM) is an independent prognostic marker for reduced survival of patients with epithelial ovarian cancer. Gynecol Oncol. 2006;103:483-8.

58. Mok SC, Elias KM, Wong K-K, et al. Biomarker discovery in epithelial ovarian cancer by genomic approaches. Cancer Res 2007. doi:10.1016/S0065-230X(06)96001-1. 